American Journal of Environmental Sciences 6 (5): 428-437, 2010

ISSN 1553-345X

(C) 2010 Science Publications

\title{
Critical Retrospect on Conventional and Luminescent Solar Concentration Devices
}

\author{
Hamzah Abdul-Rahman and Chen Wang \\ Centre for Construction Innovation and Project Management, \\ Faculty of Built Environment, University of Malaya, Kuala Lumpur, Malaysia
}

\begin{abstract}
Problem statement: Conventional solar concentrators are only sensitive for the beam radiation and they function poorly in overcast sky conditions. Even under a clear sky condition, trackers are always needed for conventional solar concentrators. Static concentrators always come with a poor concentration rate without a tracker and the light concentrated by normal Luminescent Solar Concentrators (LSC) could not be transported by optical fibers to a remote place since the light produced by LSCs is not a pointolite. Approach: Through a critical literature review and discussion, this article retrospects the merits and demerits of recent conventional solar concentrators and Luminescent Solar Concentrators (LSC). Results: Results summarized the limitations in current day lighting related solar concentration devices. As an approach for energy saving, daylight has a disadvantage of not being able to reach many areas of a building such as store rooms, basements and corridors and it also brings heat gain with the light. Light pipes were designed to transport daylight to unreached areas, but light pipes have their difficulties for wiring, so that optical fibers are considered as the best approach for the daylight transportation so far. However, the optical fiber needs a pointolite for the light transportation. Various solar concentrators that were designed using optical approaches such as using mirrors or lens for the solar energy concentration. Since they are only sensitive for the beam irradiation, they function poorly in the cloudy weather and the diffuse light conditions and even if they are under a clear sky condition, trackers are always needed. Luminescent Solar Concentrators (LSC) and some static solar concentrators were then designed as the diffuse light solution and the static solution, respectively. Static concentrators always come with a low concentration rate without a tracker and the light concentrated by normal LSCs could not be transported by optical fibers to a remote place since the light produced by an LSC is not a pointolite. Conclusion/Recommendations: New solar concentration systems need to be developed to mitigate the above-mentioned limitations. Future studies especially cross disciplinary researches on developing new solar concentrators in mitigating those limitations as discussed in this study are highly recommended.
\end{abstract}

Key words: Day lighting related device, light pipe, optical fiber, luminescent solar concentrators

\section{INTRODUCTION}

Besides the rapidly rising price of petroleum, anthropogenic activities, especially the burning of fossil fuels, have released pollutants into the atmosphere increasing global warming and depleting the ozone layer (Mills, 2002) To improve the situation there needs to be a decrease in energy of which fossil fuel is used. As a result there has been an increased interest in renewable energy systems. Solar energy is made widely available for thermal applications, day lighting and direct production of electricity (Muhs, 2000; Reisfeld and Jorgensen, 1982; Rahoma, 2008). Artificial lighting is one of the major sources of electrical energy costs in office buildings, both directly through lighting energy consumption and indirectly by production of significant heat gain, which increases cooling loads. Electric lighting represents up to $30 \%$ of building electricity consumption in commercial and office buildings (Lam and Chan, 1995). The recent interest in energy efficiency and sustainability has led to the implementation of design strategies in buildings aiming at the achievement of the optimal utilization of daylight with minimum energy consumption for lighting and cooling. Sun light as a clean energy source could contribute considerably to a solution of the energy problem if appropriate methods were developed to collect, concentrate, store and convert solar irradiation,

Corresponding Author: Chen Wang, Centre for Construction Innovation and Project Management, Faculty of Built Environment, University of Malaya, Kuala Lumpur, Malaysia 
which is diffuse and intrinsically intermittent (Reisfeld and Jorgensen, 1982). Daylight is an underused resource that has the potential to improve the quality of indoor lighting, as well as to substantially reduce energy costs.

However, daylight has a disadvantage that it may not able to reach many areas such as storerooms, basements and corridors. It also brings heat gain with the light (Hazami et al., 2005; Bouchet and Fontoynont, 1996; Shao et al., 1998). Light pipes were designed to transport the daylight to the deeper parts in buildings. However, the light pipes have their difficulties for wiring so that daylight transportation through optical fibers is considered as the best approach so far (Enedir and Tinker, 2006; Cariou et al., 1982). In building integration, one of the most important features of the remote light transportation is the wiring method and the wiring method is expected to be as simple as that of electrical wires (Enedir and Tinker, 2006; Cariou et al., 1982; Nihei et al., 1997). Only optical fibers are suitable for this requirement. However, the optical fiber needs a pointolite for it to transport (Cariou et al., 1982; Nihei et al., 1997). Solar concentrators have been designed using optical approaches such as using mirrors and/or lens because of the high price for PV cells. Since they are only sensitive for the beam irradiation, they function poorly in the cloudy weather and the diffuse light conditions and a tracker is always needed. Luminescent Solar Concentrators (LSC) and some static solar concentrators were then designed as the diffuse light solution and the static solution respectively (Weber and Lambe, 1976; Goetzberger and Greubel, 1977; Rapp and Boling, 1978). Static concentrators always come with a poor concentration rate without a tracker and the light concentrated by normal LSCs could not be transported by optical fibers to a remote place since the light produced by an LSC is not a pointolite (Kandilli et al., 2008). This study introduces the delighting related solar concentration devices such as light pipes (or tubular daylight guidance systems), optical fibers for light transport, conventional solar concentrators and Luminescent Solar Concentrators (LSC). The principles of study, advantages and disadvantages for application of these day lighting related solar concentration devices are explained.

Optical fiber for light transportation: According to (Enedir and Tinker, 2006), since the early 1990s, fiber optic cables using an artificial light source have been used in remote-source lighting systems. Using this technology, light travels from its source to one or more remote points through fiber optic cables. The technology has been used in many applications such as museums and retail displays and in architectural applications to emphasize the features of a building or to outline its exterior contours; other applications have involved lighting exit signs and aisles in theatres and aero planes etc. to name but a few.

The idea of concentrated solar energy transport by optical fibers was put forward in 1980 by a group of French investigators (Cariou et al., 1980). Owing to the unavailability of high quality optical fibers and the high cost of their design, this project limited itself to theoretical analysis only. With the present day availability of fiber-optic techniques, solar energy can be transmitted by high quality optical fibers of large core diameter and large numerical aperture. With flexible fiber optic solar energy transmission and concentration, a solar laser or any other light powered tool will be able to be moved out of its actual pumping position in the focusing area of the primary parabolic mirror and will find new applications (Cariou et al., 1980).

Wherever the remote lighting system has been introduced in an architectural project, it was mentioned clearly the practical advantages it breeds. In addition, the main light generators being put away at some distance, in a dry place, gives clear evidence about the safety higher degree of the system. Actually, in important projects where optical fibers take aim to satisfy more complex lighting design purposes, like illumination, safety is appreciated but is not certainly seen as the stimulus of the system choice. Additionally, the practical location of the effective light sources is valued but in terms of lower cost services. In fact, the main advantage aimed for while selecting a remote lighting system instead of an ordinary one, relates to some extent to the considerable cut down upon the effective running costs (Cariou et al., 1980).

The use of concentrated solar energy and its transport in optical fibers is studied by Cariou et al. (1982). Transmission properties of fibers as well as geometrical conditions of the association between fibers and concentrator were investigated. It was shown that modules where one fiber is associated with a small parabolic mirror might supply $2 \mathrm{~W}$ with efficiency greater than $70 \%$, whilst the concentration on the exit end of a $10 \mathrm{~m}$ long fiber may exceed 3000. Such a device has been achieved and the experimental results are in good agreement with the preliminary study (Cariou et al., 1982).

Conventional solar concentrators: Sunlight holds considerable unrealized potential for application in energy efficient room lighting designs. There are currently few existing systems that efficiently utilize 
sunlight to provide sufficient room lighting to remote non-daylit rooms. Anidolic optics can be used for lighting of a room with an immediate day lighting aperture. Recently, systems involving concentrating collectors, heliostats (Pohl and Anslem, 2002), or mirror light pipes (Garcia-Hansen and Edmonds, 2003) have been developed for illumination of remote rooms. A fatal disadvantage of conventional solar concentrators is while systems using mirrors or lens may be advantageous for large-scale room lighting, they chiefly rely on beam solar irradiation and require tracking mechanisms to avoid astigmatism and other light losses experienced during collection of solar energy so that they lose their functions in cloudy and diffuse conditions (Zaibel et al., 1995). Figure 1 presents an example of the heliostats solar concentrator and light transmission through optical fibers developed by Kandilli et al. (2008).

Solar concentrators were early brought into consideration as alternative ways to reduce the cost of photovoltaic electricity and solar heat due to the relatively high material and production costs of solar cells and solar thermal absorbers. One approach is to use concentrators that increase the irradiance on the modules or absorbers and thus the electricity or heat production per unit receiver area, which in turn reduces the area needed for a given output (Brogren et al., 2004).

Concentrating systems use lenses or reflectors to focus sunlight onto the solar cells or solar thermal absorbers. High concentration of solar radiation requires tracking of the sun around one axis or two axes, depending on the geometry of the system. The higher the concentration, the more concentrator material per unit area of solar cell or thermal absorber area is generally needed. It is therefore more appropriate to use lenses than reflectors in highly concentrating systems, because of their lower weight and material costs.

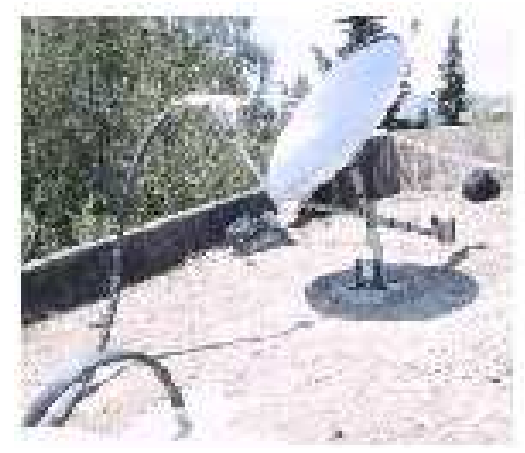

Fig. 1: One example of the heliostats solar concentrator and light transmission through optical fibers (Kandilli et al., 2008)
Lenses, typically point-focus or linear-focus Fresnel lenses with concentration ratios of 10-500 are most often manufactured out of inexpensive plastic material with refracting features that direct light onto a small or narrow area of photovoltaic cells or on a linear thermal absorber. The cells are usually silicon cells. Single or mono-crystalline silicon approaches accounted for $93 \%$ of the annual cell production in 2002. Cells of GaAs and other compound materials have higher conversion efficiencies than silicon and can operate at higher temperatures, but they are often substantially more expensive (Swanson, 2000). Concentrator module efficiencies range from $17 \%$ and upwards and concentrator cells have been designed with conversion efficiencies in excess of 30\% (Yamaguchi and Luque, 1999; Fraas et al., 1990). However, concentrator systems that utilize lenses are unable to focus scattered light, limiting their use to areas with mostly clear weather (Yamaguchi and Luque, 1999).

In areas with a lot of diffuse irradiation, as well as for moderate (5-20x) and low (less than 5x) concentration ratios, reflectors are often more cost effective than lenses and therefore the most common type of concentrator. Below $5 \times$ concentration, it is possible to construct cost-effective static concentrators, both for photovoltaic and solar thermal systems (Whitfield et al., 1995; Hellstrom et al., 2003).

These are mostly two-dimensional parabolic troughs or plane booster reflectors. Plane mirrors in front of the collector area increase the collected energy with $20-50 \%$ and reduce some of the diurnal variation (McDaniels et al., 1975). Reflectors for solar energy applications should fulfill a number of requirements (Brogren et al., 2004):

- They should reflect as much as possible of the useful incident solar radiation onto the absorbers

- The reflector material and its support structure should be inexpensive compared to the solar cells or thermal absorbers onto which the reflector concentrates radiation

- The high reflectance should be maintained during the entire lifetime of the solar collector or photovoltaic module, which is often longer than 20 years

- If cleaning is necessary, the surface should be easily cleaned without damaging its optical properties and the maintenance should not be expensive

- The construction must be mechanically strong to resist hard winds, snow loads, vibrations

- The reflector should preferably be lightweight and easy to mount 
- The reflector material should be environmentally benign and should not contain any hazardous compounds

- The visual appearance of the reflector should be aesthetical, since solar concentrators often are large and must be placed fully visible on open spaces so that the concentrator aperture is not shaded by objects in the surroundings

The optical requirement that must be fulfilled for reflector materials in solar thermal applications is a high reflectance in the entire wavelength range of the solar spectrum (300-500 $\mathrm{nm})$. In lighting and photovoltaic applications, photons with lower energy than the band gap of the solar cell, which corresponds to wavelengths longer than about $1100 \mathrm{~nm}$ for a silicon cell, do not contribute to the photoelectric conversion but only to overheating. Hence, metals that are free electron-like are suitable as reflectors for solar thermal applications, but not optimal for lighting and photovoltaic applications. There are no known metals that combine a low reflectance in the near-infrared with a high reflectance in the ultraviolet and in the visible (Mwamburi et al., 2000).

Among the Drude metals, silver and aluminum are the best solar reflectors with a solar hemispherical reflectance of approximately 97 and $92 \%$, respectively (Granqvist, 2003). Due to its lower cost, the material, which is most often used for solar reflectors today, is anodized aluminum. However, if the anodized aluminum is not protected, for example by a glazing, a plastic foil, or a lacquer, its optical performance degrades severely in only a couple of months (Bouquet et al., 1987). The degradation of silver is essentially as rapid as that of aluminum (Czanderna, 1981). Due to the limited corrosion resistance of the free electron-like metals, they are often used in back surface mirrors, evaporated on the back of a glass or polymer substrate that protects the metal from oxidation. Among the state-of-the art in solar reflector materials are Polymethylmethacrylate (PMMA) or back-surface-silvered low-iron glass (Schissel et al., 1994). However, glass mirrors tend to be brittle and heavy. Front surface mirrors, on the other hand, are often bendable and of lightweight, but more susceptible to chemical attack (Roos et al., 1989).

A solar reflector is not subject to the same high temperatures and thermal cycling as a solar absorber. Nevertheless, environmental conditions impose stringent demands on the material, whose surface will deteriorate more or less upon exposure to the environment. Loss of solar reflectivity can result from erosion or oxidation of the surface, dirt accumulation on the reflector and action of cleaning agents (Duffie, 1962). While degradation caused by accumulation of dust on the reflecting surface is essentially reversible, surface oxidation is not. The optical performance of solar reflectors thus depends on the mechanical and chemical properties of the surface and the protective coating, if such is present. For flexible reflective foils, a support of sheet metal may be necessary, while only a simple frame construction is needed if the reflector is self-supporting, which is the case for corrugated sheets. When installing booster reflectors, the cost of the reflector material, the frame and support construction, as well as mounting and installation of the reflector must be taken into account. Maintenance should also be included in lifecycle cost (Morris, 1980).

De la Mora et al. (2009) reported using Porous Silicon Photonic Mirrors (PSPM) as secondary reflectors in solar concentration systems. The PSPM were fabricated with nanostructure porous silicon to reflect light from the visible range to the near-infrared region $(500-2500 \mathrm{~nm})$, although this range could be tuned for specific wavelength applications. The PSPM are multilayer of two alternated refractive indexes (1.52.0 ), where the condition of a quarter wavelengths in the optical path was imposed. The PSPM were exposed to high radiation in solar concentrator equipment as shown in Fig. 2. As a result, it observed a significant degradation of the mirrors at an approximated temperature of $900 \mathrm{oC}$. In order to analyze the origin of the degradation of PSPM, it was modeled the samples with a non-linear optical approach and study the effect of a temperature increase. It concluded that the main phenomenon involved in the breakdown of the photonic mirrors is of thermal origin, produced by heterogeneous expansion of each layer (Mora et al., 2009).

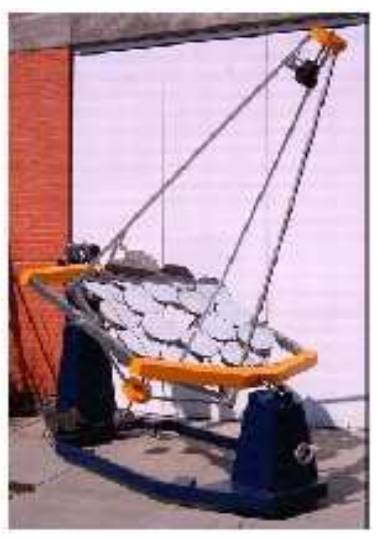

Fig. 2: DEFRAC-Spanish acronym of device for the study of highly concentrated radioactive fluxes (Estrada et al., 2007) 
Am. J. Environ. Sci., 6 (5): 428-437, 2010

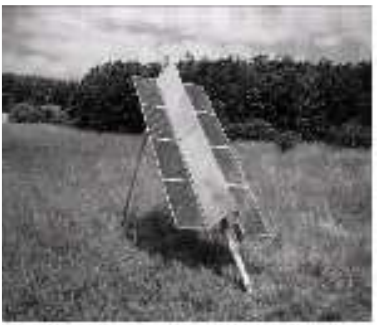

Fig. 3: Photograph of the polar axis tracking ridge with $8 \times 55$ Wp PV panels (Poulek and Libra, 2000)

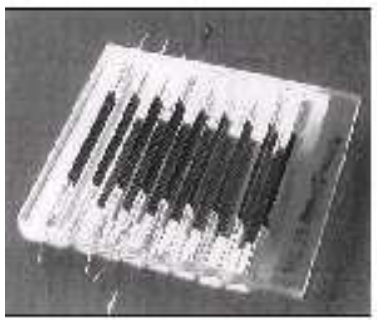

Fig. 4: Photograph of a static prism-array concentrator module (Uematsu et al., 2001)

Poulek and Libra (2000) developed a tracking ridge concentrator using proven tracker hardware. This system combines simple low-cost tracker with flat booster mirrors but unlike V-trough concentrator (Klotz, 1995; Nann, 1990) by the new ridge concentrator the mirror has been eliminated as shown in Fig. 3. On polar axis trackers with seasonally adjustable slope of the axle the extended mirror is not needed.

Unlike V-concentrator trough concentrators, no additional mirror supporting structures are needed. However, it could only double solar energy gain of PV panels in comparison with fixed ones (Poulek and Libra, 2000).

To obtain cost-effective photovoltaic modules, Uematsu et al. (2001) have developed static prism array concentrator modules consisting of prism concentrators about $4 \mathrm{~mm}$ thick assembled unidirectional under a 3.2mm-thick cover glass as shown in Fig. 4. Calculating the optical collection efficiency for the annual solar irradiation in Tokyo, it found that the theoretical efficiency of the modules is $94.4 \%$ when the geometrical concentration ratio is 1.88 and that it is $89.1 \%$ when that ratio is 2.66 , respectively. Fabricating prism-array-concentrator modules with a geometrical concentration ratio of 2.66 , it only obtained a maximum optical collection efficiency of $82 \%$ with a flat reflector and $81.7 \%$ with a V-grooved reflector (Uematsu et al., 2001).
In order to remove the trackers, a static solar concentrator is proposed by Morimoto and Maruyama (2005) to match the aesthetic features of towns. The concentrator consists of vertical plate solar cells and white/transparent switchable bottom plate, which is operated with external power. The bottom is switched to be a diffuse reflection white surface when the cell generates electric power and switched to be a light transmissible transparent surface when the cell does not deliver power. The light collection of this concentrator was analyzed by using multiple total internal reflection model and ray tracing simulation. However, the results are not significantly satisfying for a static solution for solar concentration (Morimoto and Maruyama, 2005).

Luminescent Solar Concentrator (LSC): The luminescent planar solar concentrator was proposed in the late 1970s (Weber and Lambe, 1976; Goetzberger and Greubel, 1977; Rapp and Boling, 1978) consisting of a transparent plastic sheet doped with organic dyes. Sunlight is absorbed by the dye and then re-radiated isotropically, ideally with high quantum efficiency and trapped in the sheet by internal reflection. A stack of sheets doped with different dyes can separate the light. Solar cells can be chosen to match the different luminescent wavelengths to convert the trapped light at the edge of the sheet (Goetzberger and Greubel, 1977).

Luminescent Solar Concentrators (LSCs) have attracted the attention of a large number of scientists and engineers since the first proposal by Weber and Lambe (1976). The operation of the LSC, which can be considered as a peculiar kind of light guide, is based on the following principles. One or more high quantum yield species are dissolved in a rigid highly transparent medium of high refractive index. Solar photons entering the plate are absorbed by the luminescent species and reemitted in random directions. Following Snell's law, a large fraction of the emitted photons will be trapped within the plate and transported by total internal reflections to the edge of the plate, as illustrated in Fig. 5, where they will be converted by appropriate photovoltaic cells (Richards, 2006; Reisfeld, 2001; Batchelder et al., 1979; Hammam et al., 2007).

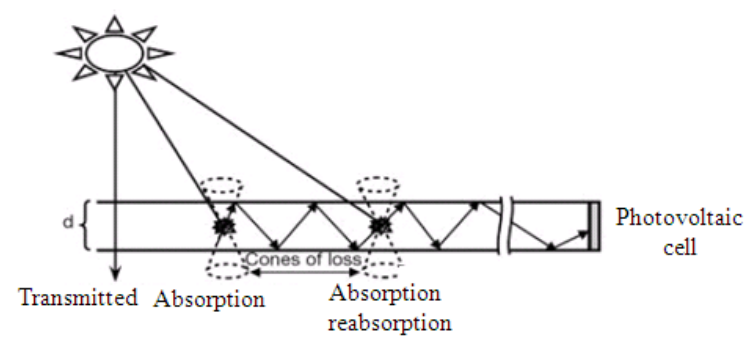

Fig. 5: Schematic representation of Luminescent Solar Concentrator (LSC) (Hammam et al., 2007) 
Conversion of the incident solar spectrum to monochromatic light would greatly increase the efficiency of solar cells. Since LSC were proposed in 1970s, solar cells were attached to it. LSCs consist of a highly transparent plastic, in which luminescent species, originally organic dye molecules, are dispersed. These dyes absorb incident light and isotropically emit it at a red-shifted wavelength, with high quantum efficiency. Internal reflection ensures collection of part of the emitted light in the solar cells at the sides of the plastic body. The energy of the emitted photons ideally is only somewhat larger than the band gap of the attached solar cells, to ensure near-unity conversion efficiency (Goetzberger and Greubel, 1977). A large fraction of the emitted photons loses from the escape cones. The size and form of the cross-section could impact on the proportion of photons trapped by the LSC plate and the reduction of the cross-sectional area of the luminescent plate could increase the photon loss (Richards, 2006; Reisfeld, 2001; Batchelder et al., 1979; Hammam et al., 2007).

LSCs were developed as an alternative approach to lower the costs of PV. As both direct and diffuse light is concentrated by a factor of 5-10, without the need for expensive tracking, smaller silicon or other solar cells can be used. As the cost of the transparent plastic is expected to be much lower than the area cost of the solar cell the cost per Watt-peak is lower compared to the cost of a planar silicon solar cell (Batchelder et al., 1979; Hammam et al., 2007). The development of the LSC was initially limited by the performance of the luminescent dyes available some decades ago. Nevertheless, efficiencies of up to $4 \%$ have been reported for a stack of two plates $(40 \times 40 \times 0.3 \mathrm{~cm})$, one being coupled to a GaAs solar cell and the other to a $\mathrm{Si}$ solar cell (Wittwer et al., 1984). Particular problems were the poor stability of the dyes under solar irradiation and the large re-absorption losses owing to significant overlap of the absorption and emission.

Within the full spectrum project (Luque et al., 2005) the performance of both quantum dots and organic dyes are being evaluated as the luminescent species in the LSC. The important characteristics of organic dyes are that they: (i) can provide extremely high luminescence quantum efficiency (near unity), (ii) are available in a wide range of coolers and, (iii) new molecular species are now available with better reabsorption properties that may also provide the necessary UV stability. Quantum dots have advantages over dyes in that: (i) their absorption spectra are far broader, extending into the UV, (ii), their absorption properties may be tuned simply by the choice of nanocrystal size and (iii) they are inherently more stable than organic dyes. Moreover, (iv) there is a further advantage in that the red-shift between absorption and luminescence is quantitatively related to the spread of quantum dot sizes, which may be determined during the growth process, providing an additional strategy for minimizing losses due to reabsorption (Barnham et al., 2000). However, as yet quantum dots can only provide reasonable luminescence quantum efficiency: Luminescence quantum efficiency more than 0.8 has been reported for core-shell quantum dots (Peng et al., 1997).

Advantages over geometric luminescent concentrators include that solar tracking is unnecessary and that both direct and diffuse radiation can be collected and, in addition, the sheets are inexpensive. However, the development of this promising concentrator was limited by the stringent requirements on the luminescent dyes, namely high quantum efficiency, suitable absorption spectra and red shifts and stability under illumination (Goetzberger et al., 1985; Wittwer et al., 1981). Concentration ratios of 10x were achieved (Goetzberger et al., 1985; Wittwer et al., 1981). A typical measured electrical efficiency with a two-stack concentrator with GaAs solar cells was $4 \%$, whereas the original predictions were in the range 1323\% (Goetzberger and Greubel, 1977).

Barnham et al. (2000) have proposed a novel concentrator in which the dyes are replaced by quantum dots. The first advantage of the quantum dots over dyes is the ability to tune the absorption threshold simply by choice of dot diameter. For example, colloidal InP quantum dots, separated by dot size, have thresholds, which span the optical spectrum (Micic et al., 1997). Secondly, high luminescence quantum efficiency has been observed. $\mathrm{CdSe} / \mathrm{CdS}$ hetero-structure dots have demonstrated luminescence quantum yields of above $80 \%$ at room temperature. Thirdly, since they are composed of crystalline semiconductor, the dots should be inherently more stable than dyes (Chatten et al., 2003).

The disappointing results obtained with dye concentrators were probably mainly because of reabsorption, which was considered, but not modeled at the time of the original calculations (Goetzberger and Greubel, 1977). Barnham et al. (2000) have argued that there is a further advantage in that the red shift between absorption and luminescence is quantitatively related by the thermodynamic model to the spread of quantum dot sizes, which can be determined during the growth process. The ability to limit the overlap between the luminescence and absorption by the choice of quantum dot size distribution is a significant improvement compared to dye concentrators (Micic et al., 1994). 
Goldschmidt et al. (2009) demonstrated how the collection efficiency of fluorescent concentrator systems is increased by two independent measures. One approach is to combine different dyes to enlarge the used spectral range. A system using the combination of two materials had an efficiency of $6.7 \%$. The other approach is to increase the collection efficiency by the application of a photonic structure, which acts as a band stop reflection filter in the emission range of the dye. A relative efficiency increase of $20 \%$ with a commercially available filter was achieved. With the achieved efficiency of $3.1 \%$ and concentration ratio of 20 , the realized fluorescent concentrator produces about 3.7 times more energy than that of the used GaInP solar cell produced on its own. Photonic structures are especially beneficial for larger systems. Goldschmidt et al. (2009) clarified the role of a white bottom reflector and its interaction with the photonic structure. The white bottom reflector increases the efficiency by two mechanisms. It increases the absorption of light in the fluorescent concentrator as it reflects non-absorbed light back into the fluorescent concentrator and it directly reflects light towards the solar cells. The second mechanism is especially important for small distances from the solar cell (Goldschmidt et al., 2009).

An LSC day lighting system has been produced by Earp et al. (2004), which transports sunlight to remote areas of a building using a stack of pink, green and violet LSCs and clear PMMA (poly methyl methacrylate) light guides. In direct sun of intensity 100,000 LUX, prototypes with collector area of $1.2 \times 0.135 \times 0.002 \mathrm{~m}^{3}$ deliver 1000 lumen of near-white light with a luminous efficacy of $311 \mathrm{Lm} \mathrm{W}^{-1}$ and a light-to-light efficiency up to $6 \%$. The light-to-light efficiency of the violet sheet is $0.29 \%$ and that of the green sheet is $5.8 \%$. The light-to-light efficiency of the pink sheet is $1.5 \%$. Surface effects such as excess adhesive and variations in flatness are thought to be causing unnecessary light loss, which can be avoided by careful LSC production (Earp et al., 2004). A limitation in the wiring for long distance light transportation has emerged in this LSC system.

\section{MATERIALS AND METHODS}

The objective of this article is to identify the working principles and to extract the limitations of the present solar concentration devices. Through a critical literature review, this study has introduced the dayligting related devices such as light pipes (or tubular daylight guidance systems), optical fibers for light transport, conventional solar concentrators and Luminescent Solar Concentrators (LSC). The principles of work, advantages and disadvantages for application of these solar concentration devices have been explained.

\section{RESULTS AND DISCUSSION}

Table 1 summarizes the limitations in current day lighting related solar concentration devices. In building integration, one of the important features of remote light transportation is the wiring method and the wiring method is expected to be as simple as that of electrical wires (Enedir and Tinker, 2006; Cariou et al., 1982). As illustrated in Table 1, only optical fibers are competent for this requirement. For instance, an LSC developed by Earp et al. (2004) is transported by polymer sheets instead of the optical fibers because the light produced by the LSC is not a pointolite. The polymer sheets have a disadvantage in wiring, which brings difficulties in building integration. It is also not energy-efficient to further concentrate the rectangular light produced by the LSC into a pointolite for the transportation through optical fibers to a remote place in a building.

There are two groups of solutions that are practiced in the building sector for general energy issues, namely: The building energy saving approaches and the renewable energy application approaches. As an approach for energy saving, daylight has a disadvantage of not being able to reach many areas of a building such as store rooms, basements and corridors and it also brings heat gain with the light (Bouchet and Fontoynont, 1996; Shao et al., 1998). Light pipes were designed to transport daylight to unreached areas, but light pipes have their difficulties for wiring, so that optical fibers are considered as the best approach for the daylight transportation so far. However, the optical fiber needs a pointolite for the light transportation. Various solar concentrators that were designed using optical approaches such as using mirrors or lens for the solar energy concentration. Since they are only sensitive for the beam irradiation, they function poorly in the cloudy weather and the diffuse light conditions and even if they are under a clear sky condition, trackers are always needed. Luminescent Solar Concentrators (LSC) and some static solar concentrators were then designed as the diffuse light solution and the static solution, respectively. Static concentrators always come with a low concentration rate without a tracker and the light concentrated by normal LSCs could not be transported by optical fibers to a remote place since the light produced by an LSC is not a pointolite. 
Am. J. Environ. Sci., 6 (5): 428-437, 2010

Table 1: Summary of limitations in current day lighting related solar concentration devices

\begin{tabular}{|c|c|}
\hline Methods and devices & Problems and Limitations \\
\hline Direct day light & $\begin{array}{l}\text { It may not able to reach many areas such as store room, basement, hallway and it } \\
\text { also brings heat gain with the light }\end{array}$ \\
\hline Light pipes & Difficulties in wiring \\
\hline Optical fiber & Needs a pointolite for it to transport \\
\hline Various solar concentrators & $\begin{array}{l}\text { They are only sensitive for beam irradiation, they do not function well in cloudy } \\
\text { weather and diffuse conditions and a tracker is always needed }\end{array}$ \\
\hline Luminescent Solar Concentrators (LSC) & $\begin{array}{l}\text { Light concentrated by normal LSC could not be transported by optical fibers to a } \\
\text { remote place since the light produced by LSC is not a pointolite. }\end{array}$ \\
\hline Static solar concentrators & Poor concentration rate without a tracker \\
\hline
\end{tabular}

\section{CONCLUSION}

This study has introduced the delighting related solar concentration devices such as light pipes (or tubular daylight guidance systems), optical fibers for light transport, conventional solar concentrators and Luminescent Solar Concentrators (LSC). The principles of study, advantages and disadvantages for application of these day lighting related solar concentration devices have been explained. Daylight has a disadvantage of not being able to reach deeper areas in a building such as storerooms, basements and corridors and it also brings the heat gain with the light. Light pipes and optical fibers were expected to transfer daylight to unreached areas, but light pipes have their difficulties in wiring and the optical fiber needs a pointolite for the light transportation. Solar concentrators are only sensitive for the beam radiation and they function poorly in overcast sky conditions. Even under a clear sky condition, trackers are always needed for conventional solar concentrators. Static concentrators always come with a poor concentration rate without a tracker and the light concentrated by normal luminescent solar concentrators could not be transported by optical fibers to a remote place since the light produced by LSCs is not a pointolite. Future studies especially cross-disciplinary researches on developing new solar concentration devices in mitigating those limitations as discussed in this study are highly recommended.

\section{REFERENCES}

Barnham, K., J.L. Marques, J. Hassard and P. O'Brien, 2000. Quantum-dot concentrator and thermodynamic model for the global red-shift. Applied Phys. Lett., 76: 1197-1199. DOI: 10.1063/1.125981

Batchelder, J.S., A.H. Zewail and T. Cole, 1979. Luminescent Solar Concentrators. Theory of operation and techniques for performance evaluation. Applied Opt., 18: 3090-3110. DOI: 10.1364/AO.18.003090
Bouchet, B. and M. Fontoynont, 1996. Daylighting of underground spaces: Design rules. Energy Build., 23: 293-298. DOI: 10.1016/0378-7788(95)00954-X

Bouquet, F.L., R.G. Helms and C.R. Maag, 1987. Recent advances in long-lived mirrors for terrestrial and space allocations. Solar Energy Mater. Solar Cells, 16: 423-433. DOI: 10.1016/0165-1633(87)90035-9

Brogren, M., A. Helgesson, B. Karlsson, J. Nilsson and A. Roos, 2004. Optical properties, durability and system aspects of a new aluminum-polymerlaminated steel reflector for solar concentrators. Solar Energy Mater. Solar Cells, 82: 387-412. DOI: 10.1016/j.solmat.2004.01.029

Cariou, J.M., J. Dugas and L. Martin, 1982. Transport of solar energy with optical fibers. Solar Energy, 29: 397-406. DOI: 10.1016/0038-092X(82)90076-7

Cariou, J.M., L. Martin and J. Dugas, 1980. Advances in ceramics. Phys. Fiber Opt., 2: 557-563.

Chatten, A.J., K.W.J. Barnham, B.F. Buxton, N.J. EkinsDaukes and M.A. Malik, 2003. A new aroach to modeling quantum dot concentrators. Solar Energy Mater. Solar Cells, 75: 363-371. DOI: 10.1016/S0927-0248(02)00182-4

Czanderna, A.W., 1981. Stability of interfaces in solar energy materials. Solar Energy Mater. Solar Cells, 5: 349-377. DOI: 10.1016/0165-1633(81)90071-X

De la Mora, M.B., O.A. Jaramillo, R. Navaa, J. Taguena-Martinez and J.A. Rio, 2009. Viability study of porous silicon photonic mirrors as secondary reflectors for solar concentration systems. Solar Energy Mater. Solar Cells, 93: 1218-1224. DOI: 10.1016/j.solmat.2009.01.007

Duffie, J.A., 1962. New materials in solar energy utilization. Solar Energy, 6: 114-118. DOI: 10.1016/0038-092X(62)90041-5

Earp, A.A., B.S. Geoff, F. Jim and S. Paul, 2004. Optimization of a three-color luminescent solar concentrator day lighting system. Solar Energy Mater. Solar Cells, 84: 411-426. DOI: 10.1016/j.solmat.2004.02.046 
Enedir, G. and J.A. Tinker, 2006. Evaluating the potential for energy savings on lighting by integrating fiber optics in buildings. Build. Environ., 41: 1611-1621. DOI: 10.1016/j.buildenv.2005.06.013

Estrada, C.A., O.A. Jaramillo and R. Acosta, 2007. Arancibia-Bulnes, Heat transfer analysis in a calorimeter for concentrated solar radiation measurements. Solar Energy, 81: 1306-1313. DOI: 10.1016/j.solener.2006.11.016

Fraas, L.M., V. Sundaram, V.S. Dinh, V.T. Davenport and T.M. Yerkes et al., 1990. Over 35\% efficient $\mathrm{GaAs} / \mathrm{GaSb}$ stacked concentrator cell assemblies for terrestrial alications. Proceedings of the 21st IEEE Photovoltaics Specialists Conference, 21-25 May, IEEE Xplore Press, Org, Orlando, FL., pp: 190-195. DOI: 10.1109/PVSC.1990.111616

Goetzberger, A. and W. Greubel, 1977. Solar energy conversion with fluorescent collectors. Applied Phys. A: Mater. Sci. Process., 14: 123-139. DOI: 10.1007/BF00883080

Goetzberger, A., W. Stahl and V. Wittwer, 1985. Physical limitations of the concentration of direct and diffuse radiation. Proceeding of the 6th European Photovoltaic Solar Energy Conference, IEEE, Reidel, Dordrecht, pp: 209-215.

Goldschmidt, J.C., M. Peters, B. Armin, H. Henning and F. Dimroth et al., 2009. Increasing the efficiency of fluorescent concentrator systems. Solar Energy Mater. Solar Cells, 93: 176-182. DOI: 10.1016/j.solmat.2008.09.048

Granqvist, C.G., 2003. Solar energy materials. Adv. Mater., 15: 1789-1803. DOI: 10.1002/adma.200300378

Hammam, M., M.K. El-Mansy, S.M. El-Bashir and M.G. El-Shaarawy, 2007. Performance evaluation of thin-film solar concentrators for greenhouse alications. Desalination, 209: 244-250. DOI: 10.1016/j.desal.2007.04.034

Hazami, M., S. Kooli, M. Lazaar, A. Farhat, A. Belghith, 2005. Thermal performance of a solar heat storage accumulator used for greenhouses conditioning. Am. J. Environ. Sci., 1: 270-277. DOI: DOI: 10.1016/j.desal.2007.04.034

Hellstrom, B., M. Adsten, P. Nostell, B. Karlsson and E. Wackelgard, 2003. The impact of optical and thermal properties on the performance of flat plate solar collectors. Renew. Energy, 28: 331-344. DOI: 10.1016/S0960-1481(02)00040-X

Kandilli, C., K. Ulgen and A. Hepbasli, 2008. Exergetic assessment of transmission concentrated solar energy systems via optical fibers for building allocations. Energy Build., 40: 1505-1512. DOI: 10.1016/j.enbuild.2008.02.021
Klotz, F.H., 1995. PV systems with V-trough concentration and passive tracking concept and economic potential in Europe. Proceedings of the 13th European PV Solar Energy Conference, Oct. 23-27, IEEE Xplore Press, Nice, pp: 1060-1063.

Lam, J.C. and A.L.S. Chan, 1995. Energy audits and surveys of air-conditioning. Proceedings of the 29th conference of Australian and New Zealand Architectural Science Association Conference, July 11-13, Australian National University Publish, Australia, pp: 49-54.

Luque, A., A. Martí, A. Bett, V.M. Andreev and C. Jaussaud et al., 2005. FULLSPECTRUM: A new PV wave making more efficient use of the solar spectrum. Solar Energy Mater. Solar Cells, 87: 467-479. DOI: 10.1016/j.solmat.2004.07.034

Morimoto, M. and T. Maruyama, 2005. Static solar concentrator with vertical flat platephotovoltaic cells and switchable white/transparent bottom plate. Solar Energy Mater. Solar Cells, 87: 299-309. DOI: 10.1016/j.solmat.2004.08.013

McDaniels, D.K., D.H. Lowndes, H. Mathew, J. Reynolds and R. Gray, 1975. Enhanced solar energy collection using reflector-solar thermal collector combinations. Solar Energy, 17: 277-283. DOI: 10.1016/0038-092X(75)90044-4

Micic, O.I., C.J. Curtis, K.M. Jones, A.J. Nozik and J.R. Sprague, 1994. Synthesis and characterization of InP quantum dots. J. Phys. Chem. B, 98: 4966-4969. DOI: $10.1021 / \mathrm{j} 100070 \mathrm{a} 004$

Micic, O.I., H.M. Cheong, H. Fu, A. Zunger and J.R. Sprague et al., 1997. Size-dependent spectroscopy of InP quantumdots. J. Phys. Chem. B, 101: 4904-4912. DOI: $10.1021 /$ jp9704731

Mills, E., 2002. The \$230-billion global lighting energy bill. Proceedings of the Right Light 5th Conference, May 2002, LBL, Nice, France, pp: 1-23. http://evanmills.lbl.gov/pubs/pdf/global_lighting_e nergy.pdf

Morris, V.L., 1980. Cleaning agents and techniques for concentrating solar collectors. Solar Energy Mater. Solar Cells, 3: 35-55. DOI: 10.1016/01651633(80)90048-9

Muhs, J.D., 2000. Design and analysis of hybrid solar lighting and full-spectrum solar energy systems. Proceedings of ASES SOLAR 2000 Conference, June 16-16, American Solar Energy Society, Madison, WI (US), pp: 1-9.

Mwamburi, M., E. Wäckelgård and A. Roos, 2000. Preparation of solar selective $\mathrm{SnO}_{\mathrm{x}}$ : $\mathrm{F}$ coated aluminum reflector surfaces. Thin Solid Films, 374: 1-9. DOI: 10.1016/S0040-6090(00)01045-2 
Nann, S., 1990. Potentials for tracking photovoltaic systems and V-troughs in moderate climates. Solar Energy, 45: 385-393. DOI: 10.1016/0038092X(90)90160-E

Nihei, E., T. Ishigure, N. Tanio and Y. Koike, 1997. Present prospect of graded-index plastic optical fiber in telecommunications. IEICE Trans. Elect., E-80-C: 117-122.

http://www.ishigure.appi.keio.ac.jp/PDFs/IEICE19 97.pdf

Peng, X., M.C. Schlamp, A.V. Kadavanich and A.P. Alivisatos, 1997. Epitaxial growth of highly luminescent $\mathrm{CdSe} / \mathrm{CdS}$ Core/Shell nanocrystals with photostability and electronic accessibility. J. Am. Chem. Soc., 119: 7019-7029. DOI: $10.1021 / \mathrm{ja} 970754 \mathrm{~m}$

Pohl, W. and C. Anslem, 2002. Natural room illumination using sunlight. Proceedings of World Renewable Energy Congress VII, June 29-July 5, Elsevier Science Ltd., Cologne, Germany, pp: 1-20.

Poulek, V. and M. Libra, 2000. A new low-cost tracking ridge concentrator. Solar Energy Mater. Solar Cells, 61: 199-202. DOI: 10.1016/S09270248(99)00103-8

Rahoma, U.A., 2008. Utilization of solar radiation in high energy intensive of the world by PV system. Am. J. Environ. Sci., 4: 121-128. DOI: 10.3844/ajessp.2008.121.128

Rapp, C.F. and N.L. Boling, 1978. Luminescent solar concentrators. Proceedings of the 13th IEEE photovoltaic specialists conference, 5-8 June 1978, IEEE Xplore Press, New York, USA., pp: 690-693.

Reisfeld, R. and C.K. Jorgensen, 1982. Luminescent Solar Concentrators for energy conversion. Solar Energy Mater., 49: 1-36. DOI: 10.1007/BFb0111291

Reisfeld, R., 2001. Prospects of sol-gel technology towards luminescent materials. Opt. Mater., 16: 17. DOI: $10.1016 / \mathrm{S} 0925-3467(00) 00052-5$

Richards, B.S., 2006. Enhancing the performance of silicon solar cells via the allocation of passive luminescence conversion layers. Solar Energy Mater. Solar Cells, 90: 2329-2337. DOI: 10.1016/j.solmat.2006.03.035

Roos, A., C.G. Ribbing and B. Karlsson, 1989. Stainless steel solar mirrors: A material feasibility study. Solar Energy Mater. Solar Cells, 18: 233240. DOI: 10.1016/0165-1633(89)90039-7
Schissel, P., G. Jorgensen, C. Kennedy and R. Goggin, 1994. Silvered-PMMA reflectors. Solar Energy Mater. Solar Cells, 33: 183-197. DOI: 10.1016/0927-0248(94)90207-0

Shao, L., A.A. Elmualim and I. Yohannes, 1998. Mirror lightpipes: Daylighting performance in real buildings. Int. J. Light. Res. Technol., 30: 37-44. DOI: $10.1177 / 096032719803000106$

Swanson, R.M., 2000. The Promise of concentrators. Prog. Photovoltaics: Res. Appli., 8: 93-111. DOI: 10.1002/(SICI)1099-159X(200001/02)8:1<93::AIDPIP303>3.0.CO;2-S

Uematsu, T., Y. Yazawa, Y. Miyamura, S. Muramatsu and H. Ohtsuka et al., 2001. Static concentrator photovoltaic module with prism array. Solar Energy Mater. Solar Cells, 67: 415-423. DOI: 10.1016/S0927-0248(00)00310-X

Weber, W.H. and J. Lambe, 1976. Luminescent greenhouse collector for solar radiation. Applied Opt., 15: 2299-2300. DOI: 10.1364/AO.15.002299

Whitfield, G.R., R.W. Bentley and J.D. Burton, 1995. Increasing the cost-effectiveness of small solar photovoltaic pumping systems. Renew. Energy, 6: 469-475. DOI: 10.1016/0960-1481(95)00038-L

Wittwer, V., K. Heidler, A. Zastrow and A. Goetzberger, 1981. Theory of fluorescent planar concentrators and experimental results. J. Luminescence, 24: 873-876. DOI: 10.1016/0022-2313(81)90108-3

Wittwer, V., W. Stahl and A. Goetzberger, 1984. Fluorescent planar concentrators. Solar Energy Mater. Solar Cells, 11: 187-197. DOI: 10.1016/0165-1633(84)90070-4

Yamaguchi, M. and A. Luque, 1999. High efficiency and high concentration in photovoltaics. IEEE Trans. Elect. Dev., 46: 2139-2144. DOI: 10.1109/16.792009

Zaibel, R., E. Dagan, J. Karni and H. Ries, 1995. An astigmatic corrected target-aligned heliostat for high concentration. Solar Energy Mater. Solar Cells, 37: 191-202. DOI: 10.1016/09270248(94)00206-1 